\title{
IMPACT OF RUSH ORDER ON SUPPLY CHAIN - CASE STUDY OF AN AUTOMOTIVE INDUSTRY
}

\author{
MARIAM HOUTI \& LAILA EL ABBADI
}

Systems Engineering Laboratory, National School of Applied Sciences Kenitra Ibn Tofail University Kenitra, Morocco

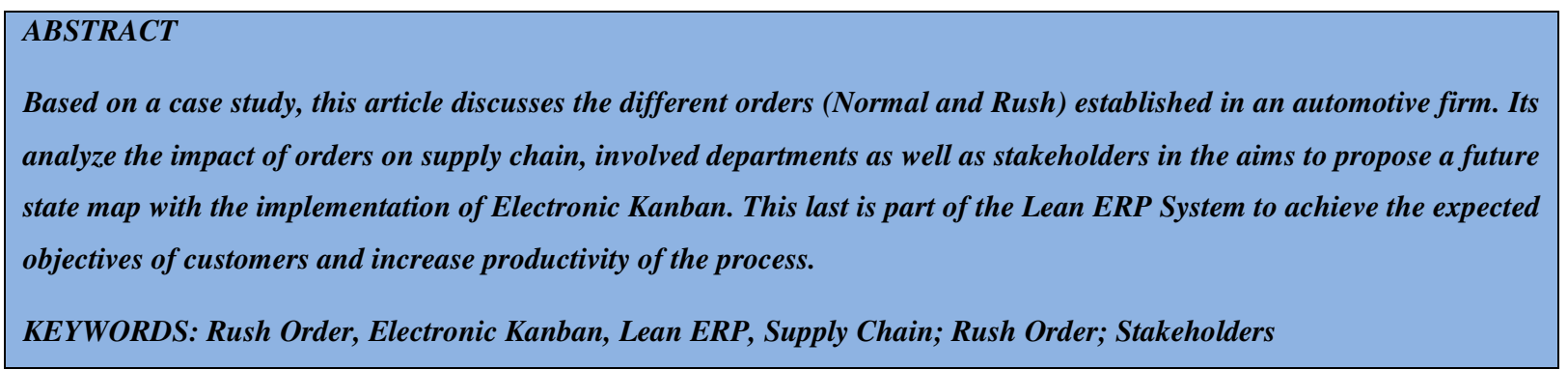

Received: Jun 08, 2020; Accepted: Jun 28, 2020; Published: Sep 10, 2020; Paper Id.: IJMPERDJUN20201143

\section{INTRODUCTION}

The automotive industry is one of the evolving large-scale industries, implying high demand with a large variability according to customer's specifications, resulting on Rush order's which causes several issues on the supply chain and its stakeholders. However, each business unit should respond to those various customer demands to remain its positions in the market, and satisfy customer requirements within agreed time, while considering their cost structures which should have in high consistency to survive [4]. Rush orders could be a big challenge for automotive enterprises especially for the supply chain project planning and delivery due to the complexity of process to different destinations.

It is in this framework, our paper will study the supply chain framework in the automotive industry within different orders established by customer and the interactions between the main departments involved in the shop floor: Logistics, production and engineering, focusing on the limitation of the classic Kanban System on Rush order.

The analysis will be based on Value stream mapping which is a significant tool of Lean Manufacturing that can serve as a good starting point for any Lean enterprise [5]; to better analyze the current state map and the problem raised due to Normal or Rush order using the classic Kanban System in order prepare a future state map with the ideal state of the manufacturing system, better methods and performance [6,7]; by the introduction of the Lean ERP System and especially the E-Kanban system to increase productivity and reduce waste.

\section{PROCESS OVERVIEW}

Each car is made up of large and small families of electrical wiring harness (see Fig. 1). Knowing that each new option of the car requires modifications within a wiring harness family, whether to add, delete or modify a branch of the concerned harness. 


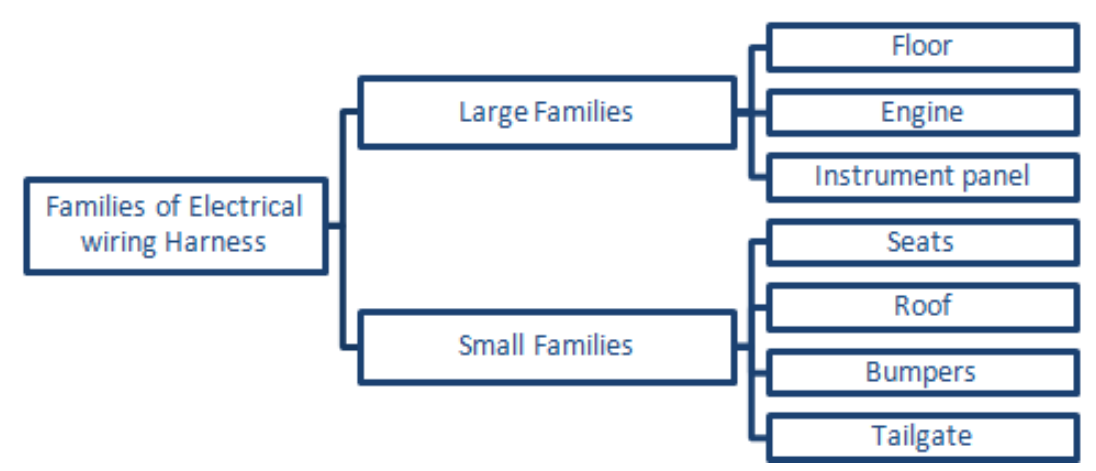

Figure 1: Families of Electrical Wiring Harness.

This production requires the assembly of several components mainly: electrical wires, connectors, terminals, etc. which are manufactured within the company or purchased from different suppliers, while ensuring that each component is designed to guarantee reliable transmission of energy and information in the vehicle. Therefore, the integration of several partners in the supply chain is used to ensure the smooth running of the supply chain which is quite complex in the automotive industry.

On the other hand, integrated partners in the supply chain could have a positive and a negative impact, since events at one partner may have impact on other partners, and their responses to these events may cause a storm of events, which are classified on three types [1]:

- Task status related events, such as the end of a task or the beginning of a task. These events are usually regular;

- Events produced by a task: for example, events "stock partially available" and "out of stock" are the result of the "check availability" task;

- External events which may arrive from other supply chain partners or from the external environment, e.g., new order arrival, inbound shipment delay, import policy change etc.

So, these Three types of events can be divided into two main categories, namely:

- Normal Order, that regroup the regular event and event caused by availability check;

- $\quad$ Rush Order, that regroup External event and especially new order arrival;

\section{CASE STUDY / CURRENT STATUS}

\section{Normal Order}

A conceptual model based on a case study on the supply chain of an automotive industry specializing in the manufacture of electrical harnesses of Seat Power Family was established in our previous work. The model links the entire supply chain from the supplier of the raw material to the customer [4].

The manufacturing process of Making an electrical harness is composed by the interaction of different department, mainly: Logistics, engineering and production department. Each department is composed with different workstation:

- Logistics Department, that insure the availability of raw material and the shipping of finished goods and which is responsible on:

- Warehouse workstation that provide the Raw material; 
- Expedition workstation;

- Creation and dispatching Kanban Card;

- Production Department, that insure the assembly and production of finished goods. It's composed of:

- Cut \& Preparation workstation: that represent two stations: the kitting and USW process;

- Assembly workstation that is reflecting the Line of the assembly of the Harness;

- Test \& controls workstation for testing the conformity and the functioning;

- Packaging workstation in order to pack the cable to deliver a finished product to the customer without problem during transportation.

\section{- Engineering Department:}

- Definition of process;

- Installation of workstations;

- Track the learning curve;

- Provide and write the necessary documentation;

- Monitoring of results and efficiency;

- Analysis of the balance between workstations;

- Improve working conditions to increase performance.

In order to make good use of our Value Stream Mapping, we need to add some data about the process and a timeline, which is essential to recognize what is suitable for the given situation, that will help us furthermore to analyze the impact of Rush order on the process data as shown in the Figure 2 below:

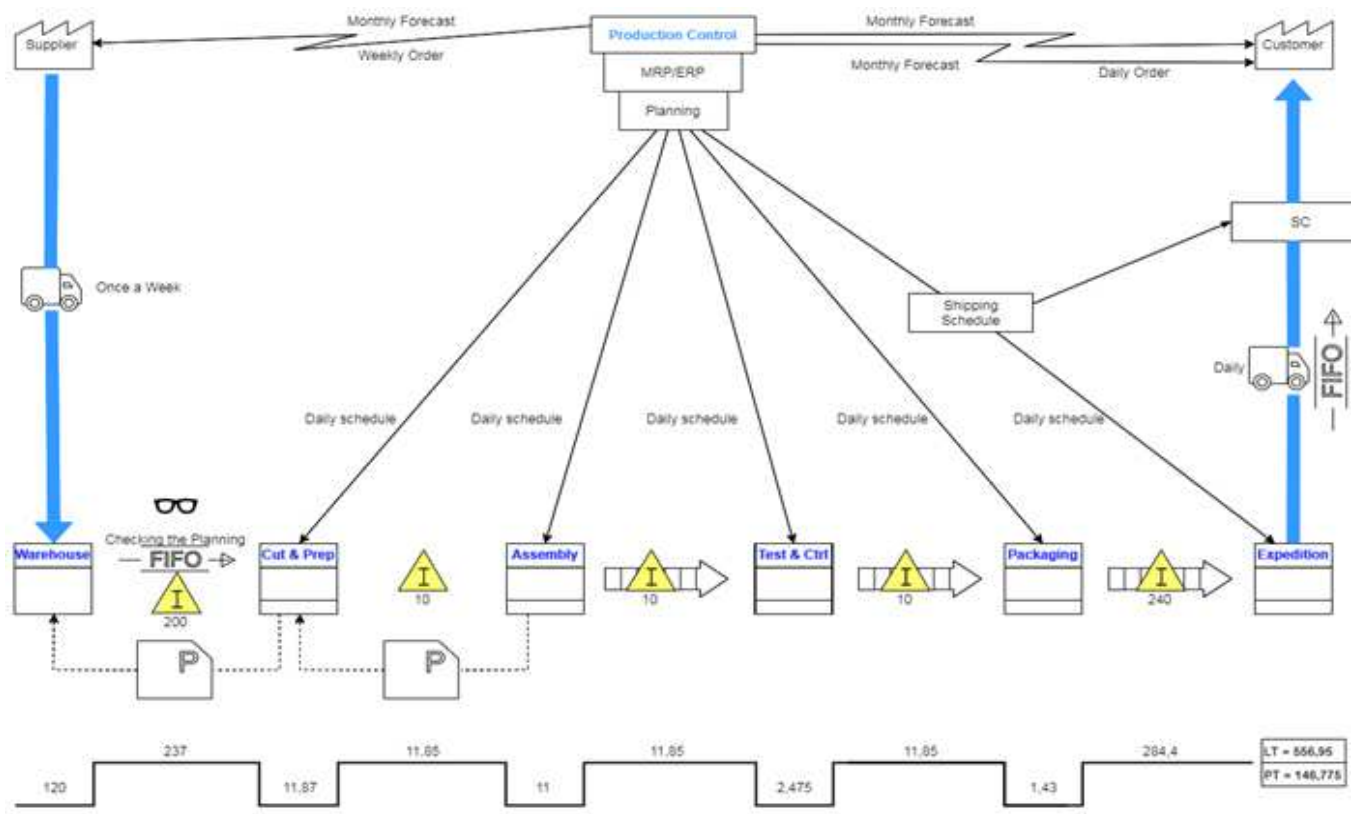

Figure 2: Timeline of a Normal Order. 
The production Line is supplied by two boxes of 100 raw materials, thereafter runs with an inventory of 10 electrical harnesses between the workstations of the Cut \& Preparation, Assembly, Test \& Control and the Packaging. Later it will reach 240 of finished good at the packaging level to fill the pallet with its maximum capacity which will be delivered to the customer.

Below the data collected based on the shop floor and the timeline above for the Normal Order:

- $\quad$ Available time $=460$ Minutes

- $\quad$ Customer demand $=388$ products per Shift $/ 776$ products per day

- $\quad$ Shift per day $=2$

- Number of Operators per crew: 21

- Output per crew: 350 products

- Process Time: $146,775 \mathrm{~min}$

- Lead Time: $703,735 \mathrm{~min}$

- Average Time to produce the Harness (GCSD): 24,67 min

The productivity is calculated in the firm according to the formula:

$$
\begin{aligned}
& \text { Productivity }=\frac{\text { Output per Crew * GCSD }}{\text { NombreofOp * AvailableTime }} \\
& \text { Productivity }=\frac{350 * 24,67}{21 * 460}=89,38 \%
\end{aligned}
$$

\section{Rush Order}

The new order arrival called also urgent order or Rush orders are defined as immediate customer demands which exceed the expectation of the MPS (master production schedule) [2], it's unscheduled orders in the production schedule, but produced first; they especially cause suspending standing orders and typically not completing them on time [3]. Rush orders are a phenomenon frequently faced by manufacturing companies in a dynamic market, especially by those doing OEM business (making products for others' brands) in developing countries [2], which is the case of the automotive industry and in particular electrical harness manufacturing and automotive parts companies.

In an urgent order the process of managing a normal order changes taking into account the importance of the customer in the portfolio of the company, that means if it is a significant customer he must be satisfied at all costs is needed despite the problems that may result [4].

Once a Rush order is issued, the business ensures first the availability of raw Material, to manage after that the production and shipping planning, two cases arise:

- The raw material is sufficient for the requested production, in this case the company can start manufacturing by prioritizing the Rush order; and at the same time she must place a new normal order with her supplier of raw materials. 
- The raw material does not cover the production requested, in this case the company places a new urgent order with its supplier of raw materials, which will be delivered by air in order to receive the goods as soon as possible in fact, the customer will pay all the additional costs caused by the urgent order issued.

This was the case during our attendance within the company, which received a Rush order from its main customer. The prioritizing of its order first have caused a multitude of problems at the level of several departments, mainly that of logistics and production, which will be summarized in the next VSM (Figure 3).

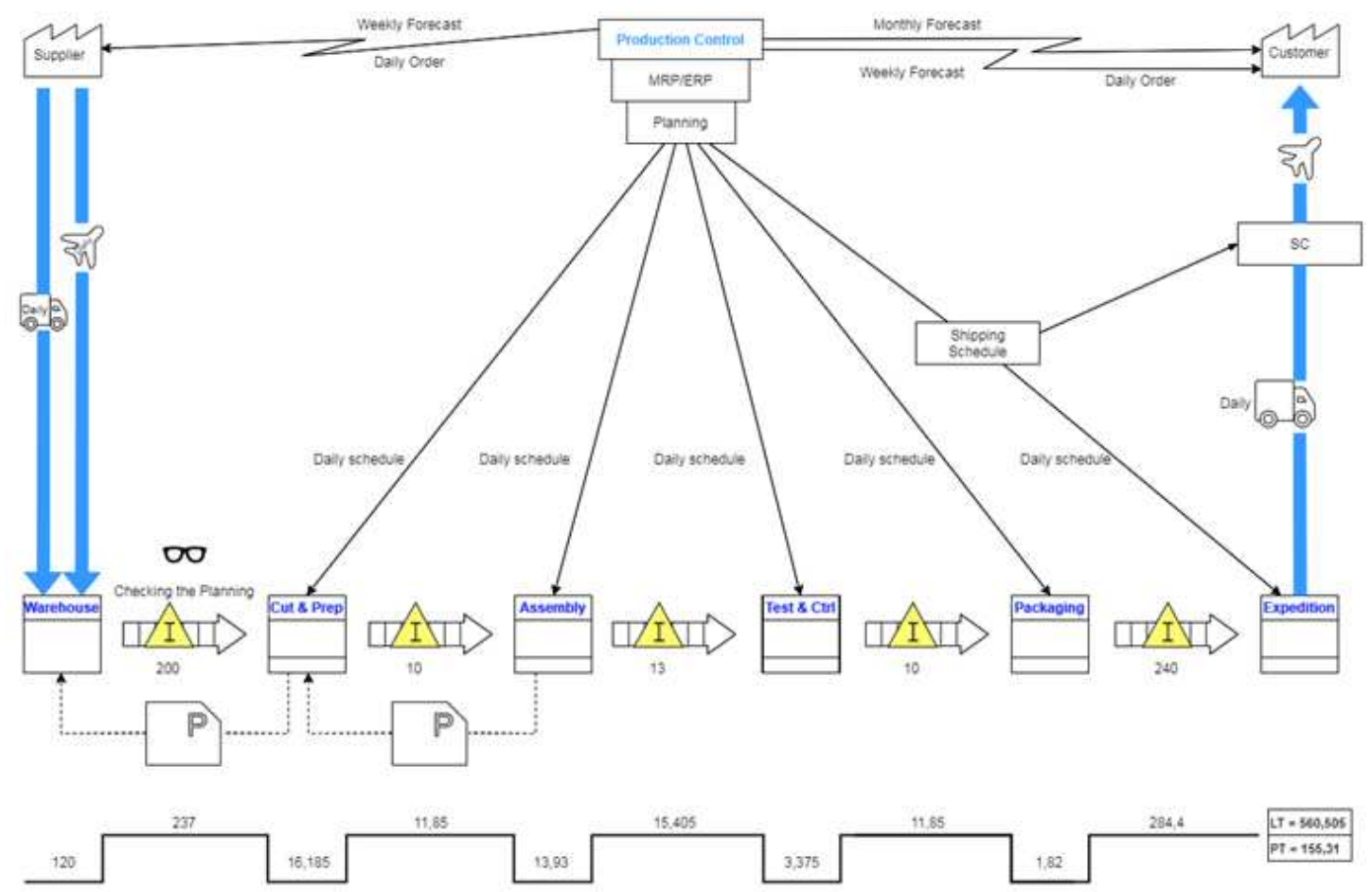

Figure 3: VSM of a Finished Good in Rush Order.

As shown in the VSM above the raw material is pushed through the supply chain and creates a stock between each workstation. This leads to high inventory, high WIP, complexity, and less space between and in cells resulting in long lead time; and the Rush Order has impacted several departments, mainly:

- Logistics Department, which have important changes to make such as:

- Change the means of transportation from land and water to Air which is very expensive

- Change of the workflow and the different providers

- Change of customs formalities and fees

- Change of times and costs of loading and unloading

- Verification of the product could be exportable by plane

- Availability of air service providers like DHL, UPS...

- Changes in insurance prices

- Workforce 
- Loading authorization

- Airport loading time

- Loading authorization.

- Production Department: The establishment of the production line is based on the capacity determined by the customer, which implies that any normal or urgent order must not exceed the maximum capacity of $100 \%$ corresponding to three teams working 8 hours a day and a number defined operators who are expert on the process, otherwise it will be necessary to redefine an adequate process for new customer's requests.

The usual request issued by the customer reaches a capacity of $66 \%$ of the production line, which results in two teams working 8 hours a day. However, with an urgent order request to reach the maximum capacity of production line. The production department has to face certain constraints such as:

- Work overtime: The two teams works 12 hours a day instead of 8 hours;

- Discouragement of Operators;

- Decrease of productivity;

- Increased testing and control;

- Add new operators;

- High number of Rework...

- Engineering Department: Supports the production department to ensure delivery in time by:

- Definition of the workstation to be Split;

- Provide adequate task to increase performance;

- Re-analyze the balance between workstations;

- Improve working conditions...

Below the data collected based on the shop floor and the timeline above for the Rush Order:

- Available time $=680$ Minutes

- Customer demand $=582$ products per shift $/ 1164$ products per day

- $\quad$ Shift per day $=2$

- Number of Operators per crew: 23

- Output per crew: 447 products

- Process Time: $155,31 \mathrm{~min}$

- Lead Time: $715,815 \mathrm{~min}$

- Average Time to produce the Harness (GCSD): 24,67 min

The productivity is calculated in the firm according to the formula: 


$$
\text { Productivity }=\frac{447 * 24,67}{23 * 680}=70,50 \%
$$

The changes should be validated by the Manufactured firm, customer and Supplier which take more time for negotiation, and automatically a delay on production and delivery time. In addition to that the Rush order generated:

- $18,88 \%$ drop in productivity;

- 8,535 min increase in Process Time;

- 12,08 min in Lead Time;

- $\quad 30 \%$ additional global cost.

\section{PROPOSED SOLUTION/ FUTURE STATE}

Our first objective is to identify and reduce the inconsistencies generated by the classic Kanban system during Rush orders, which are perceived as fluctuating demand with a high number of finished products. Therefore, it causes several problems as the case study above shows.

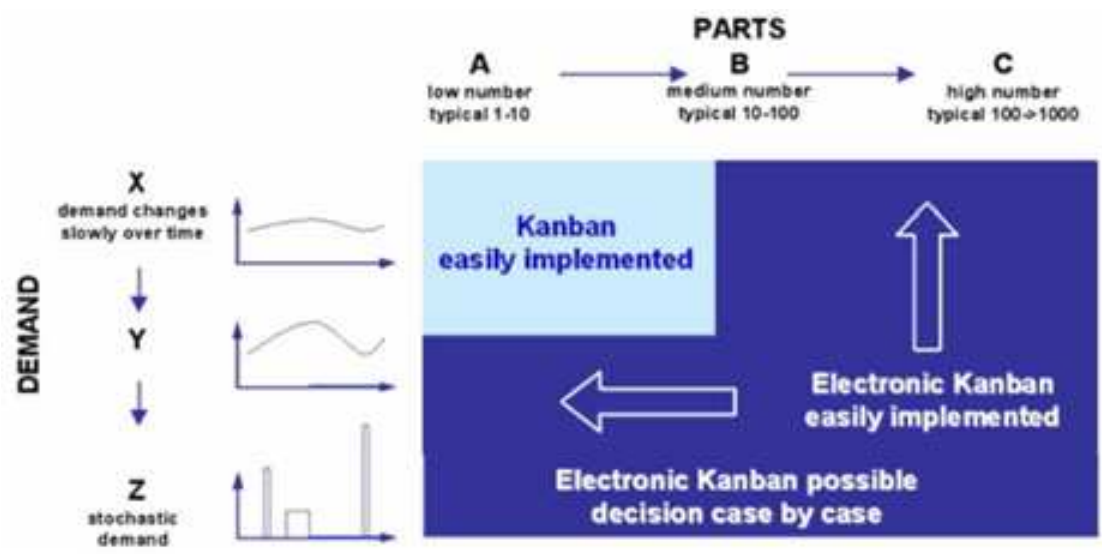

Figure 4: Areas of Application of Kanban Systems and E-Kanban [14].

As shown in the figure 4 above the Electronic Kanban system could be among the systems that can manage the Rush order, thanks to his ability to manage variable or random demand of products, or for a high number of materials that circulates in the workshop [13]

The E-Kanban system could be established from the customer to the supplier with the implication of different departments, and workstation from the warehouse, production, assembly units to the expedition. The future state map below is based on the simulation of the E-Kanban system implementation which provides realistic production design: 


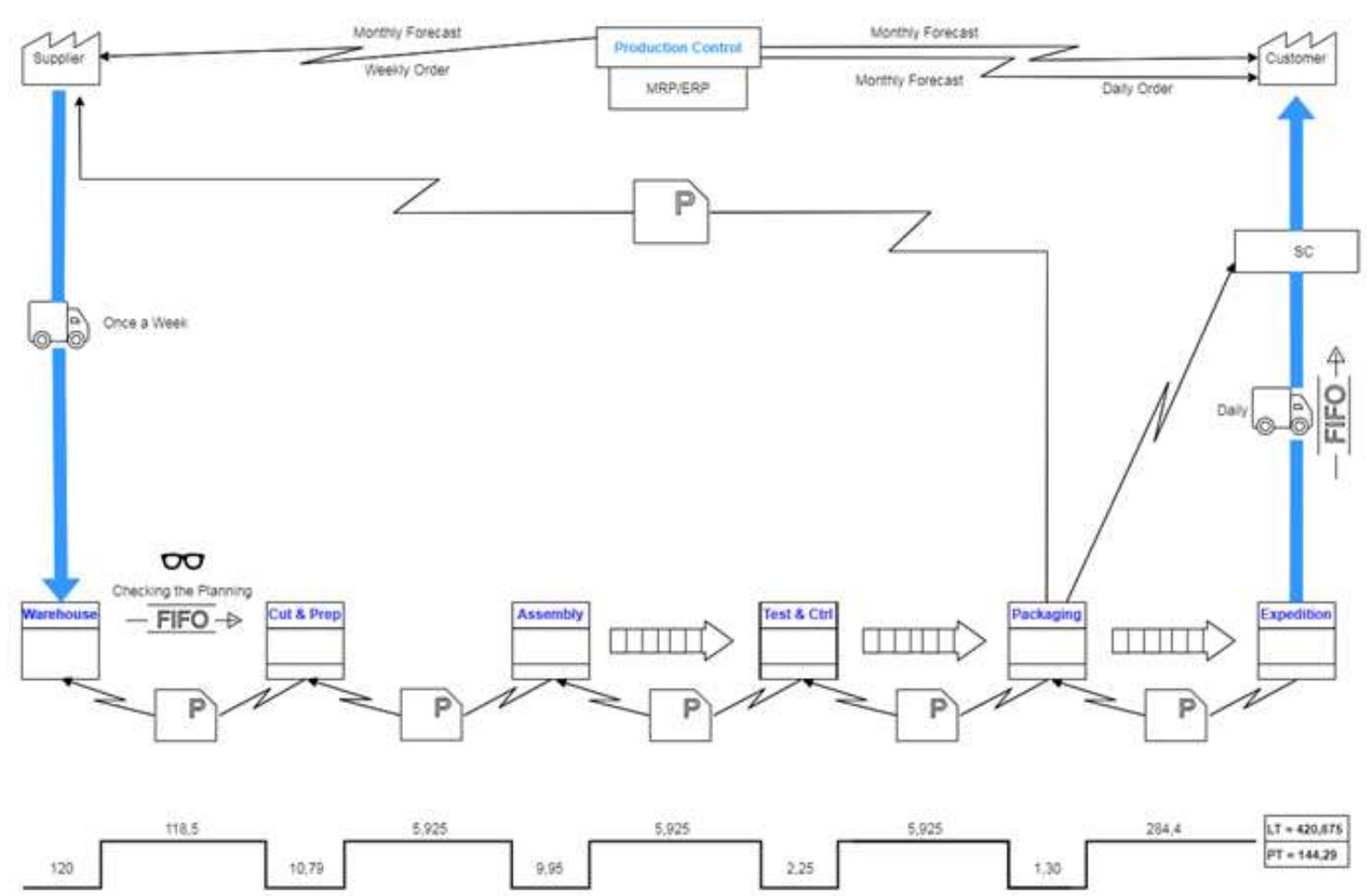

Figure 5: VSM of a Finished Good in Rush Order with E-Kanban.

E-Kanban system allows small batch sizes to perform fast processing and avoid buffering, so only one container can arrive at the workstation at a time instead of two as it 'is the case in the Current State map.

As shown in Figure 5, the workstation: test $\&$ control and cut $\&$ preparation are both bottlenecks in the process. Therefore, the physical restrictions are created through the E-Kanban system which only works effectively if a particular amount of parts are being manufactured at a time.

As shown in the VSM above: the process times and waiting times (inventory lead times) have been significantly improved compared to the Rush and normal Order, which translated on the Efficiency of the Process:

The implementation E-Kanban system, has allowed to transfer information existing in the conventional card to the Electronic ones; since the whole system is connected, it is almost the same basic system but the difference results in the computerization [13]. The issuance of a Rush order will inform automatically all the stakeholders, by an electronic information, therefore alerts will be raised to the departments concerned and decision could be made quickly. Hence the implementation of the Electronic Kanban will impact positively the three main departments, mainly:

- Logistics Department: Since many costs and waiting time are calculated by the system at the establishment of the order:

- Workflows are calculated and defined at the establishment of the System;

- Times and costs of loading and unloading calculated;

- Verification of the product could be exportable by plane already established;

- The system distinguished the air service providers available;

- Insurance pricesre calculated; 
- Authorizations that must be made are prepared at the launch of the production order;

- Obligation to follow the priority established by the planner of the production line to manufacture 3 different series of Finished Goods in the same line of production by order, instead of mixing the cards issued and starting production according to simplicity which will imply an urgent delivery since the customer must receive the delivery according to the order requested;

- Pick up of Raw Material is done by Electronic flow, which permit an accurate and efficient communication with suppliers to improve transparency of the supply chain [9].

- ElectronicKanbancard...

- Production Department: The implementation of the new system will make it possible to detect production anomalies, which will make it possible to define the specific workstation or operator in order to increase his skills or make the necessary adjustments,

- Decrease the overtime;

- Quality monitoring, the system can detect the anomaly comes from which workstation or raw material;

- Visualization of production problems by informatics tool compared to the traditional system where the problem is detected and reported by the operator [13];

- Ramp up of Operators;

- increase of productivity;

- Adequate test and control;

- Lessnumber of Rework...

- Engineering Department: Meanwhile the process is defined the team could focus on:

- Adequatetask to increase performance

- Improveworking conditions

- The learningcurve;

- The necessary documentations are already established;

- $\quad$ Effective and efficient work processes [8,10,11,12];

- Monitoring of results and efficiency is calculated by the system;

The theoretical data calculated based on the implementation of E-Kanban in a Rush Order:

- Available time $=460$ Minutes

- $\quad$ Customer demand $=388$ products per shift $/ 1164$ product per day

- $\quad$ Shift per day $=3$

- Number of Operators per crew: 21 
- Output per crew: 380 products

- Process Time: $144,29 \min$

- Lead Time: $564,965 \mathrm{~min}$

- Average Time to produce the Harness (GCSD): 24,67 min

- Productivity: $97,04 \%$

A comparison between the implementation of E-Kanban and classic Kanban for Rush Orders and Classic Kanban is summarized in the figure 6 below, which illustrate the decrease of Lead and Process Time and increase off Productivity.

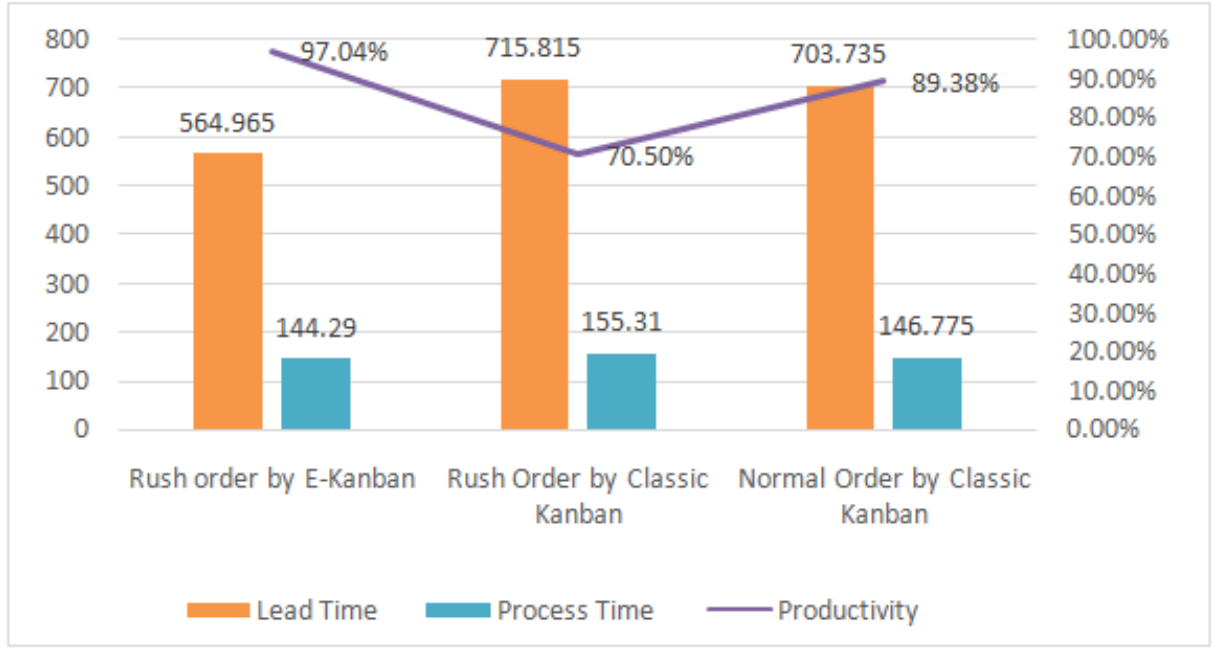

Figure 6: Comparison of E-Kanban System and Classic Kanban.

\section{CONCLUSIONS}

This article has permit to analyze the limit of the Kanban System in a Normal and Rush Order, thus as proposed solution we have simulated the Value added by implementing an Electronic Kanban which is part of the Lean ERP System, which permit to improve the process and lead Time, that imply a high Efficiency of the whole process by analyzing the interactions with the three main department in the shop floor: Logistics, production and engineering.

On the other hand, implementing the Lean ERP system should take into consideration CSFs However, to avoid failure and lead to several critical issues within the enterprise and its different stakeholders, which could be solved by taking into account the CSFS and involving different stakeholders groups during the implementation of the hybrid system [16] and classified them according management, Organization and resources to simplify the implementation [18]. In addition of that categorize the suppliers with relation to the purchasing value [17] especially potential suppliers E-Kanban that have direct relationship with the enterprise, especially when it is no longer a relationship of customers and supplier, but rather a partnership between the two organization [19].

A Study of supplier E-Kanban should be made in further research focusing on the Kanban rules, the system chosen, agreements about the delivery of Raw material, penalties, inventories, the implementation system that should be done on both Side, resistance of employees to the change. To be concluded by an Audit [15] to insure the durability of the process. 


\section{REFERENCES}

1. Rong Liu, Akhil Kumar, Wil van der Aalst. (2007). A formal modeling approach for supply chain event management. Decision Support Systems, Vol.43, (pp.761-778).

2. M.C. WU, S.Y. Chen. (1996). A cost model for justifying the acceptance of Rush orders. INT.J .PROD.RES.,vol. 34, No. 7, (pp. 1963 - 1974);

3. Sathish, T., and J. Jayaprakash. "Optimizing supply chain in reverse logistics." International Journal of Mechanical and Production Engineering Research and Development 7.6 (2017): 551-560.

4. Chun-Lung Chen. (2010). A Heuristic Model for Justifying the Acceptance of Rush Orders in Multi-Plants ManufacturingSupply Chain with Outsourcing. 8th IEEE International Conference on Industrial Informatics .Osaka, Japan.

5. Mariam Houti, Laila El Abbadi, Abdellah Abouabdellah. (2018).How Could an Urgent OrderDisturb the Supply Chain Case Study of an Automotive Industry. International Journal of Engineering \&Technology, Vol. 7, No. 4.16, (pp. 155-159).

6. Hines, P. and Rich, N. (1997). The seven value stream mapping tools. International Journal of Operations and Production Management, Vol. 17 No. 1, (pp. 46-64).

7. Kandi, Shrishail, Antriksh Mutha, and Abhay Kulkarni. "Centralization and Decentralization in Supply Chain Management." International Journal of Industrial Engineering \&Technology (IJIET) 7.3 (2017): 5-10.

8. Jones, D. and Womack, J. (2000), Seeing the Whole: Mapping the Extended Value Stream, Lean Enterprise Institute.

9. Joseph C. Chen, Ye Li \& Brett D. Shady. (2010). From value stream mapping toward a lean/sigma continuous improvement process: an industrial case study. International Journal of Production Research, Vol. 48, No. 4, (pp. 1069-1086).

10. Suprasith, J., Andrew, P.C., Thaloengsak, C., and Chayanun, K. (2011). Supply Chain EfficienciesThroughE-Kanban:A Case Study.International Journal of the Computer the Internet and Management, Vol. 19, No.1, (pp. 40-44).

11. Anyanful, Theophilus Kofi, and EmellaDedeNartey. "Critical SuccessFactors in Supply Chain Management in the Banking Sector in Ghana." Int J Bus Manag 5.1 (2015): 1-14.

12. Mayilsamy, T., Pawan, K.E. (2014). Implementation of E-Kanban System Design in Inventory Management.International Journal of Scientific and Research Publications, Vol. 4, No. 9, (pp. 2250-3153).

13. Rong, H., Fei, G., and Cheng, G. (2012). An E-kanban System for Fork Truck Assembly Lines, AppliedMechanics andMaterials, Vol. 220-223, (pp. 259-262).

14. Raju, N.M., Vijaya, E.K., Upender, G.B. (2013).Electronic Kanban System, International Journal of Scientific andResearch Publications, Vol. 3, No. 3.

15. Al-Hawari, T., Aqlan, F. (2012). A software application for E-Kanban-based WIP control in the aluminium industry. International Journal of Modelling in Operations Management, Vol. 2, No. 2, (pp. 119 - 137).

16. Akrofi, Thomas, and Ernest Ansah. "Impact of multimodal choice on any organisation's sustainable supply chain strategies." International Journal of Business Management \& Research (IJBMR) 7 (2017): 11-20.

17. Mariam Houti, Laila El Abbadi, Abdellah Abouabdellah. (2017). E-Kanban the new generation of traditional Kanban system, and the impact of its implementation in the enterprise- International Conference on Industrial Engineering and Operations Management, Rabat, Morocco.

18. Suprasith, J., Andrew, P.C., Thaloengsak, C., and Chayanun, K. (2011). Supply Chain Efficiencies Through E-Kanban: A Case Study. International Journal of the Computer the Internet and Management, Vol. 19, No.1, (pp. 40-44). 
19. Lee-Mortimer, A. (2008). A continuing lean journey: an electronic manufacturer's adopting of Kanban. Assembly Automation, Vol. 28, No.2, (pp. 103-112).

20. Mariam Houti, Laila El Abbadi, Abdellah Abouabdellah. (2019). CSFs for the Implementation of the Hybrid Lean ERP System. Stakeholders Interactions. Advances in Science, Technology and Engineering Systems Journal, Vol. 4, No. 2, (pp. 443447).

21. Ramnath, B. V., Elanchezhian, C., \& Kesavan, R. (2009). Inventory Optimization Using Kanban System: A case study. The IUP Journal of Business Strategy, Vol.6, No. 2, (pp. 56-69).

22. Mariam Houti, Laila El Abbadi, Abdellah Abouabdellah. (2019). Critical Success Factors for Lean implementation"Projection on SMEs, IEOM International Conference, At Pilsen, Czech Republic.

23. Mariam Houti, Laila El Abbadi, Abdellah Abouabdellah. (2019). External Critical Successul Factors For A Successful Implementation of ERP Systems. How Digital Platforms And Industrial Engineering Are Transforming Industry And Services, At Lisbon. 